\title{
RANS and LES investigations of vertical flows in the fuel passages of gas-cooled nuclear reactors
}

DOI:

10.1115/ICONE16-48372

10.1115/ICONE16-48372

Link to publication record in Manchester Research Explorer

\section{Citation for published version (APA):}

Keshmiri, A., Cotton, M. A., Addad, Y., Rolfo, S., \& Billard, F. (2008). RANS and LES investigations of vertical flows in the fuel passages of gas-cooled nuclear reactors. In International Conference on Nuclear Engineering, Proceedings, ICONE/Int Conf Nucl Eng Proc ICONE (Vol. 2, pp. 297-306) https://doi.org/10.1115/ICONE16-48372, https://doi.org/10.1115/ICONE16-48372

\section{Published in:}

International Conference on Nuclear Engineering, Proceedings, ICONE|Int Conf Nucl Eng Proc ICONE

\section{Citing this paper}

Please note that where the full-text provided on Manchester Research Explorer is the Author Accepted Manuscript or Proof version this may differ from the final Published version. If citing, it is advised that you check and use the publisher's definitive version.

\section{General rights}

Copyright and moral rights for the publications made accessible in the Research Explorer are retained by the authors and/or other copyright owners and it is a condition of accessing publications that users recognise and abide by the legal requirements associated with these rights.

\section{Takedown policy}

If you believe that this document breaches copyright please refer to the University of Manchester's Takedown Procedures [http://man.ac.uk/04Y6Bo] or contact uml.scholarlycommunications@manchester.ac.uk providing relevant details, so we can investigate your claim.

\section{OPEN ACCESS}




\title{
RANS AND LES INVESTIGATIONS OF VERTICAL FLOWS IN THE FUEL PASSAGES OF GAS-COOLED NUCLEAR REACTORS
}

\author{
Amir Keshmiri, Mark A. Cotton, Yacine Addad, Stefano Rolfo and Flavien Billard \\ School of Mechanical, Aerospace and Civil Engineering (MACE), \\ The University of Manchester, Manchester M60 1QD, U.K.
}

\begin{abstract}
Coolant flows in the cores of current gas-cooled nuclear reactors consist of ascending vertical flows in a large number of parallel passages. Under post-trip conditions such heated turbulent flows may be significantly modified from the forced convection condition by the action of buoyancy, and the thermal-hydraulic regime is no longer one of pure forced convection. These modifications are primarily associated with changes to the turbulence structure, and indeed flow laminarization may occur. In the laminarization situation heat transfer rates may be as low as $40 \%$ of those in the corresponding forced convection case. The heat transfer performance of such 'mixed' convection flows is investigated here using a range of refined ReynoldsAveraged-Navier-Stokes (RANS) turbulence models. While all belong to the broad class of Eddy Viscosity Models (EVMs), the various RANS closures have different physical parameterizations and might therefore be expected to show different responses to externally-imposed conditions. Comparison is made against experimental and Direct Numerical Simulation (DNS) data. In addition, Large Eddy Simulation (LES) results have been generated as part of the study. Three different CFD codes have been employed in the work: 'CONVERT', 'STAR-CD', and 'Code_Saturne', which are respectively in-house, commercial, and industrial packages. It is found that the early EVM scheme of Launder and Sharma [1] is in the closest agreement with consistentlynormalized DNS results for the ratio of mixed-to-forced convection Nusselt number $\left(\mathrm{Nu} / \mathrm{Nu}_{0}\right)$. However, in relation to DNS and experimental data for forced convection Nusselt number, other models perform better than the LaunderSharma scheme. The present investigation has revealed discrepancies between direct-simulation, experimental, and the current LES studies.
\end{abstract}

Keywords: 'Eddy Viscosity Models', 'LES', 'Mixed Convection', 'RANS'.

\section{INTRODUCTION}

In the currently-operating UK fleet of Magnox and Advanced Gas-Cooled Reactor (AGR) stations, and also in proposed 'Generation IV' Very High Temperature Reactor
(VHTR) designs, the core coolant flows vertically. The coolant in the existing stations is carbon dioxide and the principal flow ascends through the core; in VHTRs the coolant is helium and the flow descends. Density variations affect the flow, and heat transfer levels with respect to the corresponding forced convection flow at the same Reynolds and Prandtl numbers may be quantified in terms of a Nusselt number ratio, $\mathrm{Nu} / \mathrm{Nu}_{0}$. Under post-trip conditions, where the heat loading is relatively large in relation to the flow rate, such buoyancy effects have the potential to cause wholesale modifications to the turbulence structure. In the ascending flow case heat transfer levels may be either impaired (at moderate heat loadings), or enhanced (at very high heat loadings). In the case of descending flow, heat transfer levels are always enhanced. The complex phenomena associated with the mixed convection regime are discussed in the monograph of Petukhov and Polyakov [2] and the review paper of Jackson et al. [3].

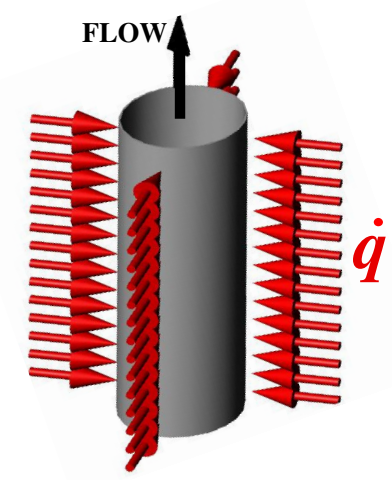

Figure 1. Schematic Diagram of an Ascending Mixed Convection Flow

Attention in the present contribution is restricted to the ascending flow case, and the geometry, which consists of a long vertical pipe, is illustrated in Fig. 1. The thermal boundary is one of uniform wall heat flux.

Experimental studies of ascending turbulent mixed convection air flows include the works of Steiner [4], Carr et al. [5], Polyakov and Shindin [6], Vilemas et al. [7] and Shehata and McEligot [8]. In contrast, Parlatan et al. [9]

\footnotetext{
* Corresponding Author: E-mail: A.Keshmiri@postgrad.manchester.ac.uk Tel: +44 (0) 1612754401
} 
used water as the working fluid. Despite the primary focus of the present work being on gas-cooled reactors, comparison with the data of Parlatan et al. is reported below. (This is justified on the basis that a 'buoyancy parameter', defined in the Nomenclature, includes a Prandtl number dependence.)

With the advent of large-scale computing facilities, new mixed convection data have become available in the form of Direct Numerical Simulations. One of the earliest DNS studies was reported by Kasagi and Nishimura [10] who carried out computations on turbulent mixed convection between two vertical parallel plates maintained at different temperatures; in the present study comparison is made with the recent results of You et al. [11] who conducted a DNS study on turbulent mixed convection in a heated vertical pipe for conditions of constant properties with buoyancy accounted for using the Boussinesq approximation. This feature of their computations enables the effects of buoyancy to be studied in isolation from other influences associated with the non-uniformity of fluid properties and flow acceleration.

Amongst other works, turbulence model results for mixed convection flows may be found in Abdelmeguid and Spalding [12], Cotton and Jackson [13], Kirwin [14] and Kim et al. [15]. The latter three works examined 'lowReynolds-number' EVMs in which viscous terms are introduced as modifications to asymptotic high-Reynoldsnumber forms. Of the models tested, it was found that the Launder-Sharma model [1] was the most accurate. (Unlike many other low-Reynolds-number variants, the LaunderSharma scheme is cast in terms of a 'turbulent Reynolds number', $\mathrm{Re}_{\mathrm{t}}$, and consequently does not make recourse to wall-distance parameters.) In the present study the authors seek to examine further the Launder-Sharma model and undertake new comparisons with two additional Eddy Viscosity Models. Large Eddy Simulation (LES) results are also reported.

\section{COMPUTATIONAL FRAMEWORKS \\ 2.1 Mean Flow Equations}

The mean flow equations are written in the 'thin shear', or 'boundary layer', and Boussinesq approximations. Thus, in Cartesian tensor notation (where $U_{j}$ represents a mean velocity component), the mean flow conservation equations are as follows:

Continuity:

$$
\frac{\partial U_{j}}{\partial x_{j}}=0
$$

\section{Momentum:}

$\rho \frac{D U_{i}}{D t}=-\frac{\partial p}{\partial x_{i}}+\frac{\partial}{\partial x_{j}}\left(\left(\mu+\mu_{t}\right) \frac{\partial U_{i}}{\partial x_{j}}\right)+\rho g_{i}\left[1-\beta\left(T-T_{0}\right)\right]$

where: $g_{i}=\left\{\begin{array}{l}-g \text { for ascending flow } \\ +g \text { for descending flow }\end{array}\right.$

Energy:

$$
\rho \frac{D T}{D t}=\frac{\partial}{\partial x_{j}}\left[\left(\frac{\mu}{P r}+\frac{\mu_{t}}{\sigma_{t}}\right) \frac{\partial T}{\partial x_{j}}\right]
$$

where, following standard modelling practice, e.g. [1], the turbulent Prandtl number is set to a constant value, $\sigma_{t}=0.9$.

\subsection{Refined Eddy-Viscosity Models implemented in an In-House Code, 'CONVERT'}

'CONVERT' (for Convection in Vertical Tubes) was originally advanced by Cotton [16] as a modification of the finite volume/finite difference code 'PASSABLE' developed by Leschziner [17]. CONVERT differs from PASSABLE in its use of the 'exact' pressure correction scheme of Raithby and Schneider [18]; the years since the appearance of [16] have seen many refinements made to CONVERT, for example Kirwin [14] extended the code to have full variable properties capabilities (i.e. the Boussinesq approximation was not adopted and therefore more extreme temperature variations could be examined). Here, however, the program is used in its original form where the mean flow governing equations are given by Eqs. (1)-(4).

The radial mesh comprises 100 control volumes and a double-expansion technique is employed to ensure good resolution of the near-wall flow (the wall-adjacent node is typically located at $y^{+}=0.5$, and approximately half the nodes are positioned between the wall and $y^{+}=60$ ). The governing equations are parabolic and small steps are taken in the axial direction to advance the solution. At-station iteration is applied to ensure a converged solution at each axial location. A number of carefully-conducted sensitivity tests have been applied here and in previous studies to ensure the numerical reliability of the results presented below.

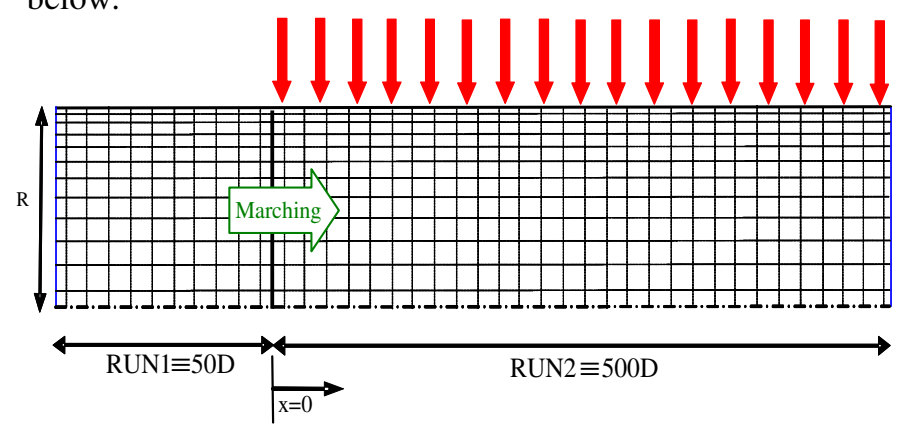

Figure 2. CONVERT Solution Sequence

Figure 2 shows the solution technique: first, an initial isothermal run ('RUN 1') is made in which the dynamic field is allowed to develop from approximate initial profiles to a fully-developed state as determined by the particular turbulence model in use. In the present work, RUN 1 was typically set to 50D. Next, a mixed convection run (RUN 2) reads the fully-developed mean flow and turbulence profiles from RUN 1 at $x=0$. A uniform wall heat flux is applied and the buoyancy force term is activated in Eq. (2). In those cases where it is required that the mixed convection run should itself reach a hydrodynamically and thermally fullydeveloped state, RUN 2 is extended 500 diameters downstream of $x=0$, although, as will be seen later, in the case of one particular EVM the domain had to be restricted to $50 \mathrm{D}$ because of convergence difficulties. 
Three EVMs have been examined using CONVERT:

1) The Launder and Sharma model [1], hereafter the 'LS model', in which the eddy, or turbulent, viscosity is formulated in terms of $k$, the turbulent kinetic energy, and $\tilde{\varepsilon}$, a modified expression for the rate of viscous dissipation of $k$. Transport equations are carried for $k$ and $\widetilde{\varepsilon}$, and, as noted previously, 'damping' (with respect to a highReynolds-number asymptotic model form) is achieved primarily in terms of a turbulent Reynolds number.

2) A three-equation scheme due to Cotton and Ismael [19], the 'CI model', in which an additional transport equation for a 'strain parameter', $S$ is included. Damping is principally in terms of $S$, with only limited dependence on $R e_{t}$.

3) The Craft-Launder-Suga non-linear EVM [20], the 'Suga model'. This closure achieves damping in a manner similar to that of the CI model, although there is no third transport equation in the Suga scheme. While the model constitutive equation incorporates quadratic and cubic functions of the mean strain rate and vorticity tensors, these terms are not significant in flows subject to simple shear. The Suga model is also implemented in STAR-CD [21] (see Section 2.4 below).

More detailed descriptions of the three turbulence models may be found in the original papers and Keshmiri et al. [22].

\subsection{Development of the 'Manchester $v^{2}-f$ Model' using 'Code_Saturne'}

Code_Saturne is a general purpose industrial CFD code developed by Electricite de France (EDF). The program is applicable to three-dimensional steady and unsteady single phase flows. A finite volume approach is adopted and variables are stored using a fully collocated arrangement [23].

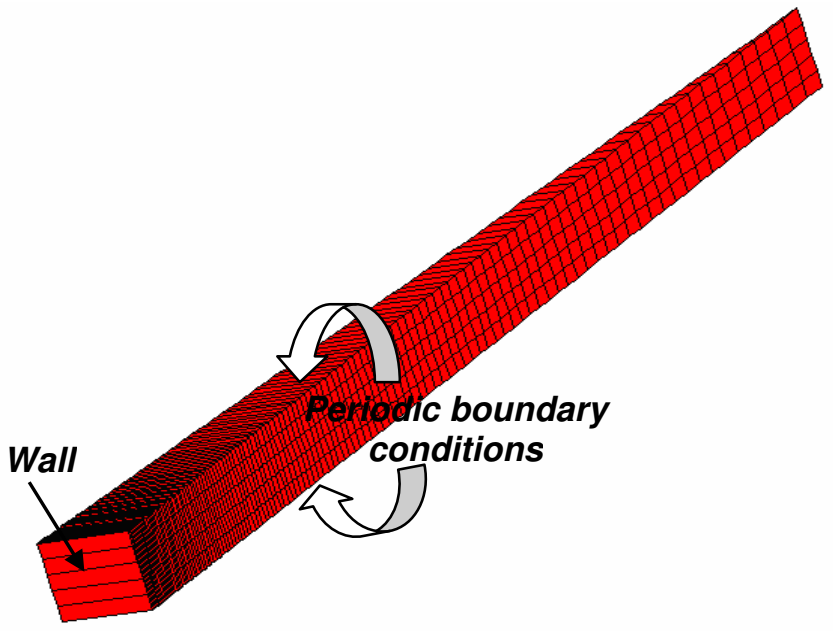

Figure 3. The Mesh used in Code_Saturne and STAR-CD

The mesh used for the present Code_Saturne (and STAR-CD, below) computations is shown in Fig. 3. The domain consists of a 2-degree sector of the pipe crosssection. Periodic boundary conditions are applied in the streamwise $(x)$ direction, while symmetry boundary conditions are applied at the two azimuthal $(\theta)$ faces. The face at $r=R$ represents the pipe wall. In principle, only one cell is necessary in the streamwise direction, however, five are used to promote convergence. There are 120 cells in the radial direction and the wall-adjacent cell is positioned at $0.15<y^{+}<0.2$.

Two eddy viscosity models are investigated in the Code_Saturne computations:

1) The first scheme is the 2-equation $k-\omega-S S T$ model of Menter [24] (where 'SST' denotes Shear Stress Transport). The model is a development of Wilcox's $k-\omega$ EVM [25] in which $\omega$, the large-scale turbulence frequency, is selected in preference to $\varepsilon$ as the subject of the second transport equation. (The model of [24] is also implemented in STAR$\mathrm{CD}$, and direct comparison of the two codes is reported in Section 3.)

2) The second model is the Manchester $\overline{v^{2}}-f$ scheme, which, in view of its recent development, is now discussed in some detail.

The original $\overline{v^{2}}-f$ model of Durbin [26] has as its starting point two-equation $k-\varepsilon$ EVMs of the type introduced above, e.g. the LS model. However, a third transport equation is included for $\overline{v^{2}}$, one of the three Reynolds normal stresses ( $v$ is the wall-normal component of the fluctuating velocity vector). $\overline{v^{2}}$ is used in a revised definition of turbulent viscosity given by the following equation:

$$
v_{t}=C_{\mu} \overline{v^{2}} T_{t}
$$

where $T_{t}=\max \left(k / \varepsilon, C_{T} \sqrt{v / \varepsilon}\right)$.

The $\overline{v^{2}}$-equation includes a redistributive source term, $f$ which represents a modelled form of the pressure-strain correlation. An elliptic equation is used in the determination of the source term, a feature that allows cognizance to be taken of non-local effects. Unfortunately, incorporation of the original scheme in an industrial segregated solver (where the governing equations are solved sequentially) may give rise to numerical problems related to the 'stiffness' of the equation set, and it is this consideration that has led to the development of a number of alternative approaches, including the current revised formulation.

Lien and Durbin [27] subsequently developed a 'code friendly' version of the scheme which sought to overcome the numerical issues alluded to above. However, a source term in the $f$-equation was neglected in the Lien-Durbin formulation, an omission that had the effect of causing the revised scheme to return results that were significantly different from those of the original model. Two later attempts were made to produce a form of the $\overline{v^{2}}-f$ closure that would be suitable for use in industrial segregated codes (Laurence et al. [28]; Hanjalić et al. [29]). The models of [28] and [29] solved a transport equation for a dimensionless variable $\varphi=\overline{v^{2}} / k$ in place of $\overline{v^{2}}$. The terms neglected in the $\varphi$-based variants were less significant than those of [27]; however, numerical problems persisted and the models were prone to be unstable, particularly in near-wall regions.

The refinement of the $\overline{v^{2}}-f$ model proposed here uses an 'elliptic blending' approach (Manceau [30]) in order to 
strengthen the coupling between $\varphi$ and $f$. Thus, an elliptic equation is solved for a 'blending parameter', $\alpha$ :

$$
L^{2} \nabla^{2} \alpha-\alpha=-1
$$

where $L=C_{L} \max \left(k^{3 / 2} / \varepsilon, C_{\eta}\left(v^{3} / \varepsilon\right)^{1 / 4}\right)$.

The blending parameter varies the weighting between a near-wall sub-model (Eq. (7), below) and a homogeneous sub-model (Eq. (8)) that appear in the $\varphi$-equation (Eq. (9)):

$$
\begin{gathered}
f_{\text {wall }}=-\frac{\varepsilon}{k} \varphi \\
f_{\text {hom }}=-\frac{1}{T_{t}}\left(C_{1}+C_{2} \frac{P_{k}}{\varepsilon}-1\right)\left(\varphi-\frac{2}{3}\right) \\
\frac{D \varphi}{D t}=\alpha^{3} f_{\text {hom }}+\left(1-\alpha^{3}\right) f_{\text {wall }}-P_{k} \frac{\varphi}{k} \\
+\frac{2}{k}\left(\frac{v_{t}}{\sigma_{k}}\right) \frac{\partial k}{\partial x_{j}} \frac{\partial \varphi}{\partial x_{j}}+\frac{\partial}{\partial x_{j}}\left[\left(v+\frac{v_{t}}{\sigma_{\varphi}}\right) \frac{\partial \varphi}{\partial x_{j}}\right]
\end{gathered}
$$

The wall boundary condition applied to Eq. (6) is $\alpha=0$, an aspect of the current proposal that greatly alleviates the problems experienced by other workers in relation to the stiffness of the equation set. The transport equations for turbulent kinetic energy and its dissipation rate read as follows:

$$
\begin{gathered}
\frac{D \rho k}{D t}=\rho P_{k}-\rho \varepsilon+\frac{\partial}{\partial x_{j}}\left[\left(\mu+\frac{\mu_{t}}{\sigma_{k}}\right) \frac{\partial k}{\partial x_{j}}\right] \\
\frac{D \rho \varepsilon}{D t}=\rho \frac{C_{\varepsilon 1} P_{k}-C_{\varepsilon 2} \varepsilon}{T_{t}}+\frac{\partial}{\partial x_{j}}\left[\left(\mu+\frac{\mu_{t}}{\sigma_{\varepsilon}}\right) \frac{\partial \varepsilon}{\partial x_{j}}\right]
\end{gathered}
$$

Table 1. Specification of the Manchester $\overline{v^{2}}-f$ model

\begin{tabular}{|c|c|c|c|c|c|c|}
\hline \multicolumn{2}{|c|}{$C_{\varepsilon 1}$} & $C_{\varepsilon 2}$ & $C_{1}$ & $C_{2}$ \\
\hline \multicolumn{2}{|c|}{$1.44\left(1+0.04\left(1-\alpha^{3}\right) \sqrt{\frac{1}{\varphi}}\right)$} & 1.83 & 1.7 & 1.2 \\
\hline$\sigma_{k}$ & $\sigma_{\varepsilon}$ & $\sigma_{\varphi}$ & $C_{\eta}$ & $C_{\mu}$ & $C_{L}$ & $C_{T}$ \\
\hline 1.0 & 1.22 & 1.0 & 90 & 0.22 & 0.22 & 6.0 \\
\hline
\end{tabular}

The functions and constants appearing in the Manchester $\overline{v^{2}}-f$ model are listed in Table 1 .

\subsection{Validation Tests using 'STAR-CD'}

STAR-CD [21] is an unstructured code and, in common with CONVERT and Code_Saturne, solves the governing equations using a finite volume approach. It is a powerful package in the sense that it performs all the necessary operations for a flow problem, including pre-processing, processing, and post-processing. It also allows the user to undertake analysis of a wide range of different flows: transient, multi-phase, and compressible, as well as combinations of these. It is also capable of carrying out simulations which may involve heat and mass transfer and chemical reaction. STAR-CD offers a wide range of RANS models in addition to having LES capabilities.

As part of the present work, STAR-CD was used to generate results using the following four turbulence models: 1) A low-Reynolds-number $k-\varepsilon$ model due to Lien et al. [31], termed the 'Standard Low-Reynolds-Number Model' in the STAR-CD documentation [21]. The formulation is similar to the LS model, however, the $\varepsilon$-equation is cast in a slightly different form, in part to improve the convergence properties of the model.

2) The 'Suga model' [20]. As noted above, this has the same form as the model implemented in CONVERT. It was found, however, that STAR-CD computations with the Suga model were highly unstable and it proved impossible to generate reliably converged simulations. In consequence, Section 3 does not include any results obtained using the STAR$\mathrm{CD} /$ Suga model combination.

3) Menter's $k-\omega-S S T$ model [24]. This model is the same as that used in Code_Saturne.

4) The $\overline{v^{2}}-f$ model of Lien and Durbin [27] (discussed above in connection with the development of the present Manchester $\overline{v^{2}}-f$ scheme). This model is also available in Code_Saturne.

\subsection{Large Eddy Simulation}

In a departure from the various Reynolds-averaged turbulence closures described above, the final set of computations undertaken in the present work consist of Large Eddy Simulations in which there is no modelling of the larger, energy-containing, turbulence structures, but where the smaller dissipative eddies are represented using a 'Sub-Grid-Scale' model. The commercial code STAR-CD (version 4.02) has been used for these computations and the small scales are modelled using the classical Smagorinsky/Lilly model. The model constant, $C_{s}$, is taken to be equal to 0.047 with the grid filter, $\Delta$, defined to be twice the cube root of the cell volume in the sub-grid viscosity expression:

$$
\mu_{t}=\left(C_{s} \Delta\right)^{2}|\bar{S}|
$$

To account for near-wall effects, Lilly [32] suggested expressing the sub-grid filter as:

$$
\Delta=\min (\kappa y, \Delta)
$$

where $\kappa=0.42$ and $y$ is the nearest distance from the wall. The turbulent Prandtl number is fixed at 0.9.

Details of the physical aspects of the LES procedures employed and the calibration of the sub-grid model are presented by Addad [33]. The current LES grid represents a full pipe section (and not a segment as in Fig. 3). Mirroring the DNS computations of You et al. [11], the current domain is made long in the streamwise direction $(=30 \mathrm{R})$ in order to avoid the generation of spurious flow-oriented spatial correlations. The resolution of the grid at the wall is $\Delta r^{+}=$ 1.0, $R \Delta \phi^{+} \approx 6.3$, and $\Delta z^{+} \approx 18.0$, while the resolution of the 
DNS grid used by You et al. was $\Delta r^{+} \approx 0.2, R \Delta \phi^{+} \approx 8.8$ and $\Delta z^{+} \approx 10.5$. Using the same LES grid, the present authors have performed 7 runs for various values of the buoyancy parameter, $\mathrm{Bo}$.

\section{RESULTS AND DISCUSSION}

Results are presented in two main sections: in the first of these, Nusselt number impairment or enhancement with respect to the Nusselt number for pure forced convection, $N u_{0}$ is examined. Fully-developed $N u / N u_{0}$ is plotted against a 'buoyancy parameter', $B o$ which was first developed by Hall and Jackson [34]. In the present work Bo is defined as:

$$
\text { Bo }=8 \times 10^{4} \mathrm{Gr} /\left(\operatorname{Re}^{3.425} \operatorname{Pr}^{0.8}\right)
$$

This form was advanced by Jackson et al. [3]. Present EVM and LES computations are compared against several sets of experimental data and the DNS results of You et al. [11].

The second group of calculations provides greater detail of thermal-hydraulic development by plotting $N u$ vs. $x / D$. However, it is the case that fewer models are employed; and comparison is made with the experimental data of Polyakov and Shindin [6].

\subsection{Computations of Heat Transfer Impairment and Enhancement}

Since forced convection Nusselt number is to supply the normalizing parameter in the presentation of heat transfer impairment/enhancement effects, it is appropriate first to assess model performance in the computation of buoyancyfree pipe flows. All runs are performed for $R e=5300$ (or $R e_{\tau}=180$ ) and $\operatorname{Pr}=0.71$, the values selected by You et al. [11] (Note, however, that the presentation below of mixed convection results in terms of the buoyancy parameter of Eq. (14) does allow cautious extrapolation to other flow conditions.)

The results of this initial assessment are summarized in Table 2 and Fig. 4 which show values of local friction coefficient and Nusselt number computed using the eight turbulence model/code combinations and single LES approach under current investigation. The first points on the left of Fig. 4 and the horizontal broken lines represent the DNS results of You et al. It is immediately apparent that, even for this simple 'baseline' case, there is significant disparity between the various schemes.

It is noted that the long-established Launder-Sharma model somewhat under-predicts the DNS values of $N u_{0}$ and $c_{f o}$. A particularly large discrepancy in the value of $N u_{0}$ is returned by the STAR-CD $k-\omega-S S T$ model (+19.7\%), while the 'Standard' $k-\varepsilon$ formulation implemented in STAR-CD produces too low a value of $c_{f o}(-17.8 \%)$. Naturally, an under- or over-prediction of $N u_{0}$ will affect the absolute level of mixed convection deduced from values of $\mathrm{Nu} / \mathrm{Nu}_{0}$ to be examined next. The DNS value of $N u_{0}$ is itself $7 \%$ lower than that found from the experiments of Polyakov and Shindin [6] (discussed further in Section 3.2 below).
Table 2. Results for Fully-Developed Forced Convection

\begin{tabular}{|c|c|c|c|c|}
\hline Models/Techniques & $\boldsymbol{N} \boldsymbol{u}_{0}$ & $\begin{array}{c}\% \\
\text { diff. }\end{array}$ & $c_{f 0}$ & $\begin{array}{c}\% \\
\text { diff. }\end{array}$ \\
\hline DNS of You et al. (2003) & 18.3 & & $9.28 E-03$ & 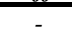 \\
\hline Expt. of Polyakov and Shindin & 19.6 & +7.1 & - & - \\
\hline Launder \& Sharma (CONVERT) & 17.4 & -4.9 & $8.52 E-03$ & -8.2 \\
\hline Cotton \& Ismael (CONVERT) & 18.9 & +3.3 & $9.17 E-03$ & -1.2 \\
\hline Suga NLEVM (CONVERT) & 18.3 & 0 & $8.93 E-03$ & -3.8 \\
\hline Standard $k-\varepsilon(S T A R-C D)$ & 17.9 & -2.2 & $7.63 E-03$ & -17.8 \\
\hline Lien \& Durbin $\overline{v^{2}}-f(S T A R-C D)$ & 17.4 & -4.9 & $9.08 E-03$ & -2.2 \\
\hline Manchester $v^{2}-f$ (Code_Saturne) & 18.6 & +1.6 & $8.95 E-03$ & -3.6 \\
\hline$k-\omega-S S T(S T A R-C D)$ & 21.9 & +19.7 & $9.84 E-03$ & +6.0 \\
\hline$k-\omega-S S T$ (Code_Saturne) & 19.8 & +8.2 & $9.62 E-03$ & +3.7 \\
\hline LES (STAR-CD) & 20.1 & +9.8 & $9.39 E-03$ & +1.2 \\
\hline
\end{tabular}

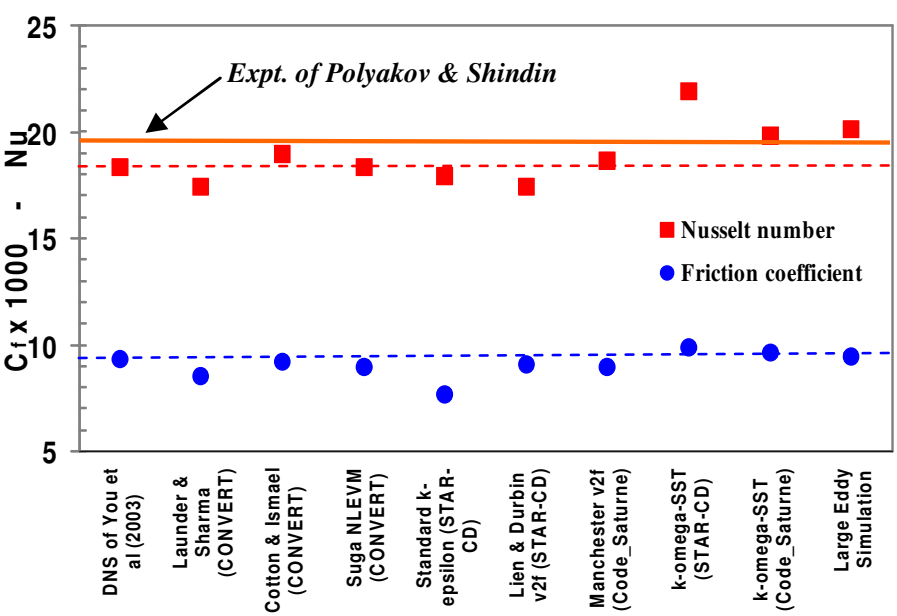

Figure 4. Results for Fully-Developed Forced Convection.

In computing mixed convection flows, You et al. retained the same Reynolds and Prandtl numbers and varied buoyancy influence via the Grashof number. A total of four simulations were performed and these are detailed in Table 3 . In each case a brief description of the thermal-hydraulic regime is included in the table. Figure 5, which shows $\mathrm{Nu} / \mathrm{Nu}_{0}$ vs. $\mathrm{Bo}$, includes the results of You et al. for Cases BD.

Table 3. DNS Cases of You et al. [11]

\begin{tabular}{|c|c|c|c|}
\hline Case & $G r / e^{2}$ & Regime description & Bo \\
\hline$A$ & 0 & Forced Convection & 0 \\
\hline$B$ & 0.252 & Early-onset mixed convection & 0.13 \\
\hline$C$ & 0.348 & Laminarization & 0.18 \\
\hline$D$ & 0.964 & Recovery & 0.50 \\
\hline
\end{tabular}

Also shown in Fig. 5 are the data of Steiner [4], Carr et al. [5] and Parlatan et al. [9]. While these data were obtained for values of $R e, P r$, and $G r$ different from those of You et al., all are cast in terms of $B o$ (which, in its nature, is an approximate quantification of buoyancy influence, [34, 3]). Another factor affecting the experimental data, but not accounted for in the DNS of You et al. or the present simulations, relates to variable property (principally viscosity) influences; this point is considered in more detail in Section 3.2, below. The final elements completing Fig. 5 are $\mathrm{Nu} / \mathrm{Nu}_{0}$ vs. $\mathrm{Bo}$ distributions computed using the various turbulence models and LES of the present study (Following 


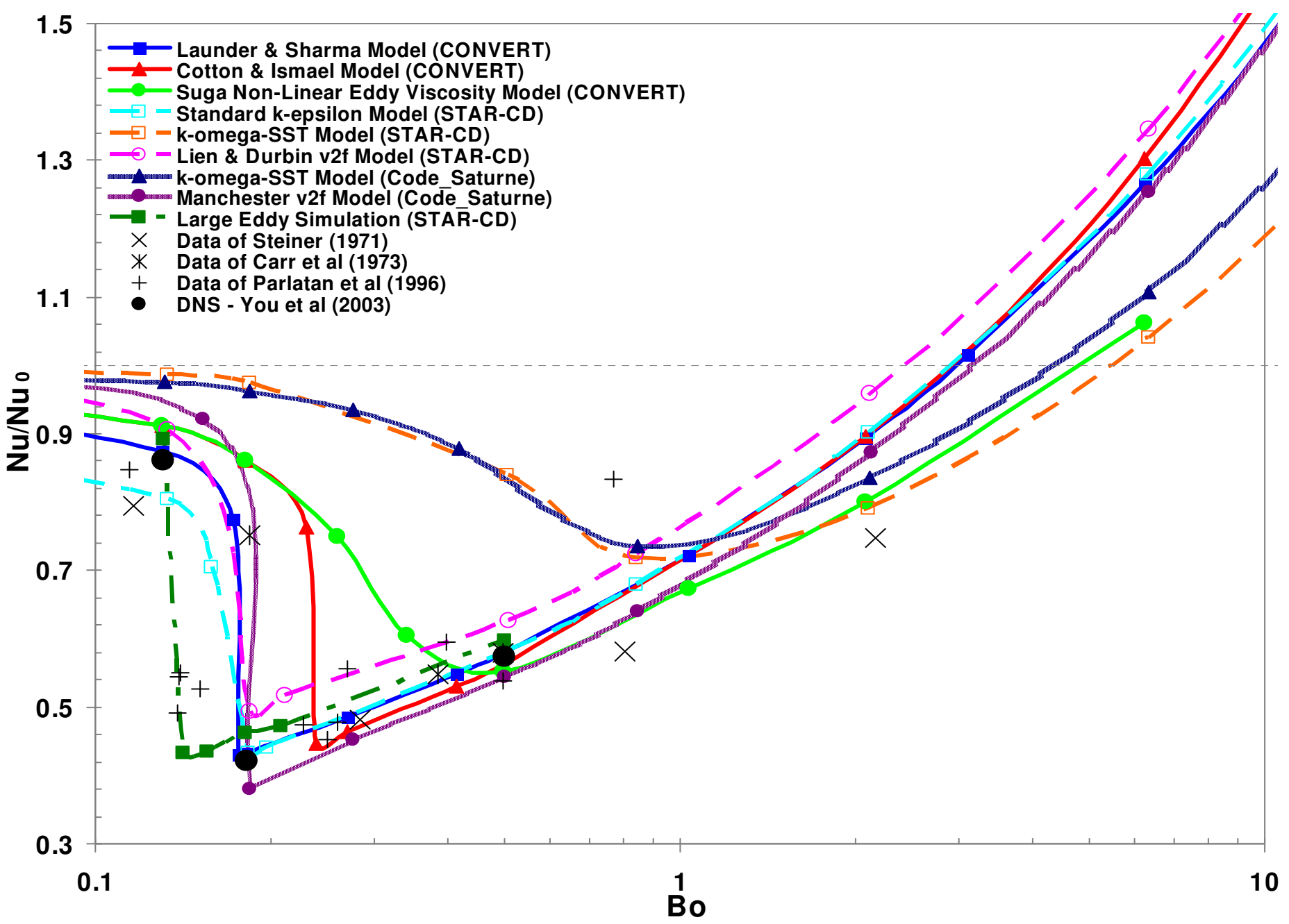

Figure 5. Nusselt Number Impairment and Enhancement

You et al., $R e$ and $\operatorname{Pr}$ were unchanged from the forced convection tests). Where available, all sets of data and the present computations are normalized using the corresponding $N u_{0}$ value of that particular test case. (However, note that some of the physical experiments represented in Fig. 5 did not report forced convection Nusselt numbers and in these cases the present authors have been obliged to use an established heat transfer correlation to normalize the mixed convection Nusselt numbers of the experiments.)

The most striking picture to emerge from Fig. 5 is the abrupt and dramatic reduction in heat transfer levels occurring at around $0.15<B o<0.25$. DNS Case C $(B o=$ $0.18)$ is representative of this laminarized state in which heat transfer levels are only approximate $4 / 10^{\text {ths }}$ of those found in forced convection under otherwise identical conditions. The formulation in closest agreement with the three DNS data points is the LS model (as implemented in CONVERT). Other models that perform well are the Manchester $\overline{v^{2}}-f$ scheme (Code_Saturne) and the Lien and Durbin $\overline{v^{2}}-f$ model (STAR-CD), although these two schemes are not as close to the DNS point at the lowest level of buoyancy influence (Case B; Bo = 0.13). The Large Eddy Simulations (STAR-CD) indicate that significant heat transfer impairment occurs at a lower value of $\mathrm{Bo}$, and interestingly these results, at least at lower levels of buoyancy influence, are in good agreement with the water data of Parlatan et al. when both the LES and data are presented in terms of $B o$.

The CI model (CONVERT) returns an unduly late onset of impairment. The Suga model (also coded in CONVERT) shows a considerable delay in the onset of heat transfer impairment and also significantly under-predicts the extent of impairment (these results are for $x / D=50$ because, for cases with relatively high $B o$, converged solutions could not be obtained at locations further downstream). The $k-\omega-S S T$ model (STAR-CD and Code_Saturne) performs particularly poorly, but there is at least quite close agreement between the two codes. Finally in relation to the turbulence models, it is observed that the 'Standard' $k$ - $\varepsilon$ model (STAR-CD) returns somewhat different results from the LS scheme, mainly for lower values of Bo. Examining the experimental data for the 'Recovery' region $(B o \geq 0.2)$, a general observation might be made that there is considerable scatter in the measurements, a feature that may be due in part to variable property effects.

\subsection{Nusselt Number Development - The Experiments of Polyakov and Shindin}

Heat transfer development is examined next and comparison is made with the experimental data of Polyakov and Shindin 


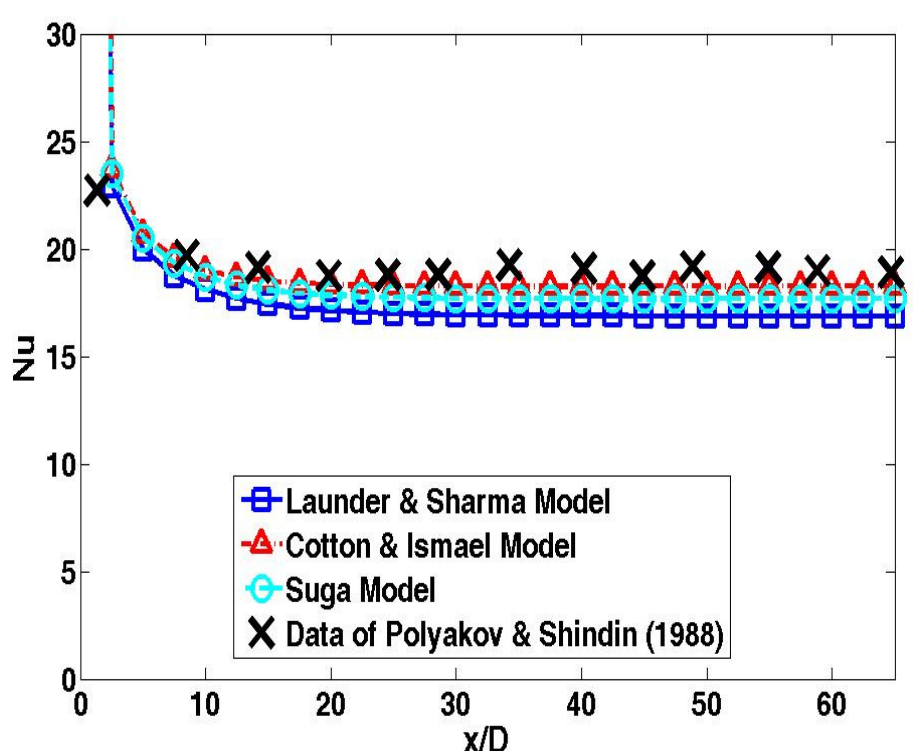

(a)

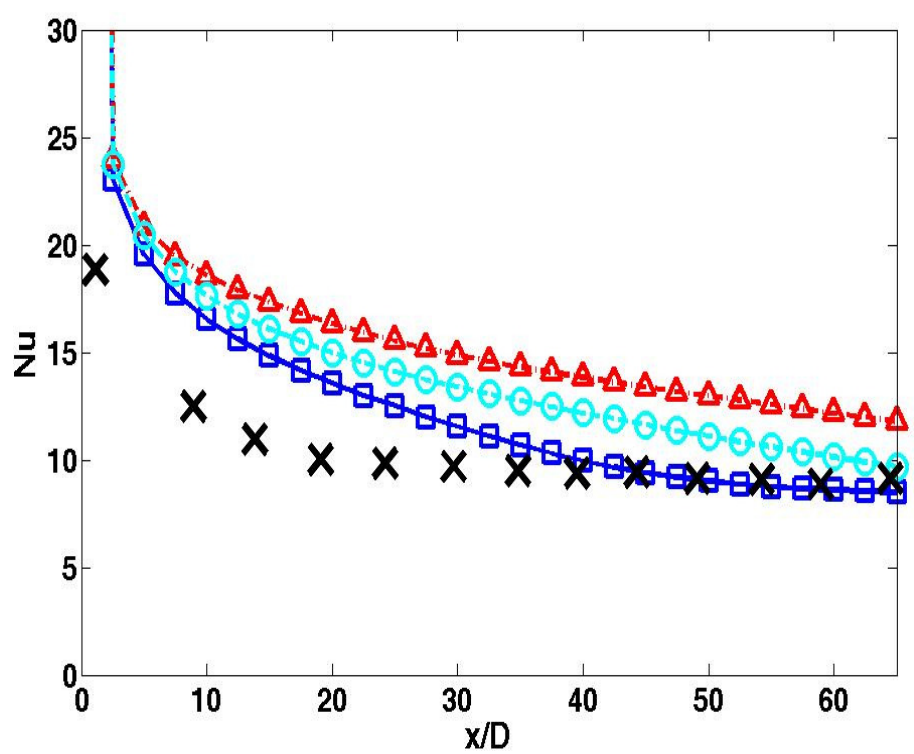

(c)

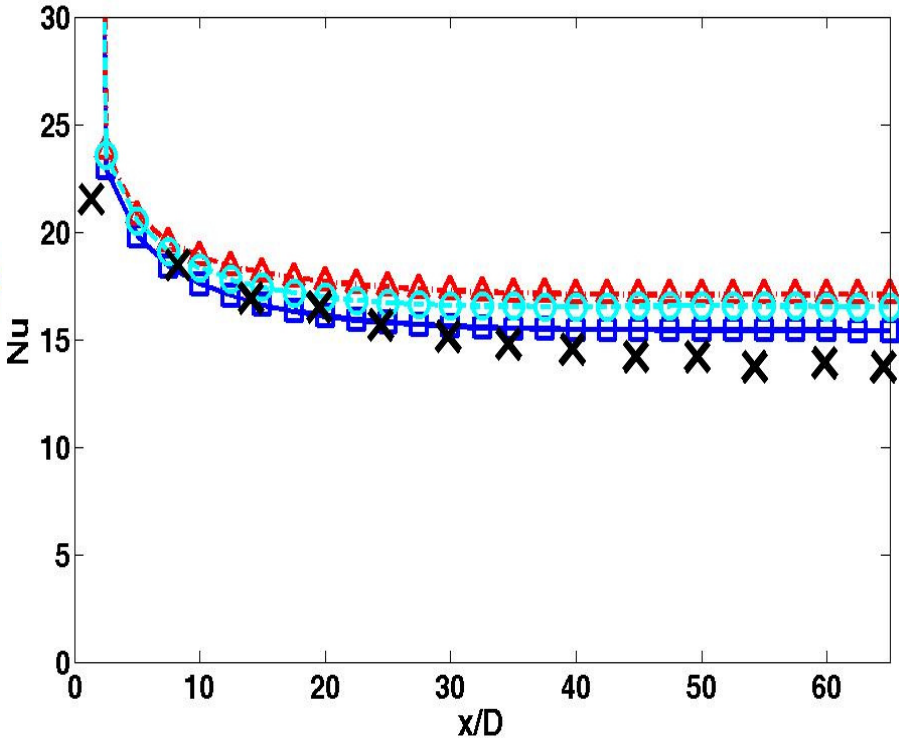

(b)

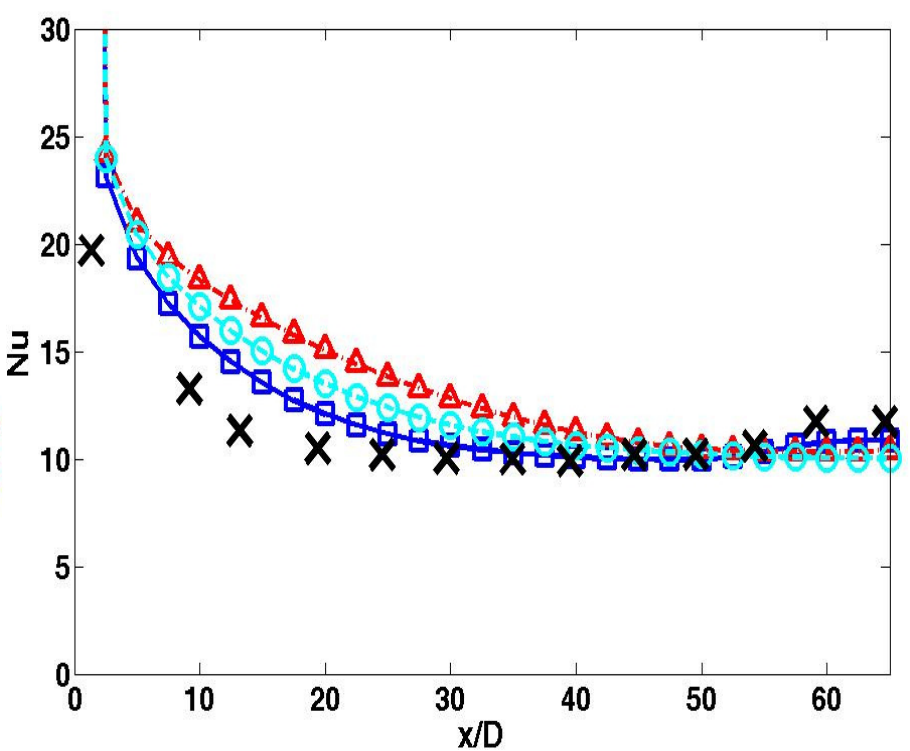

(d)

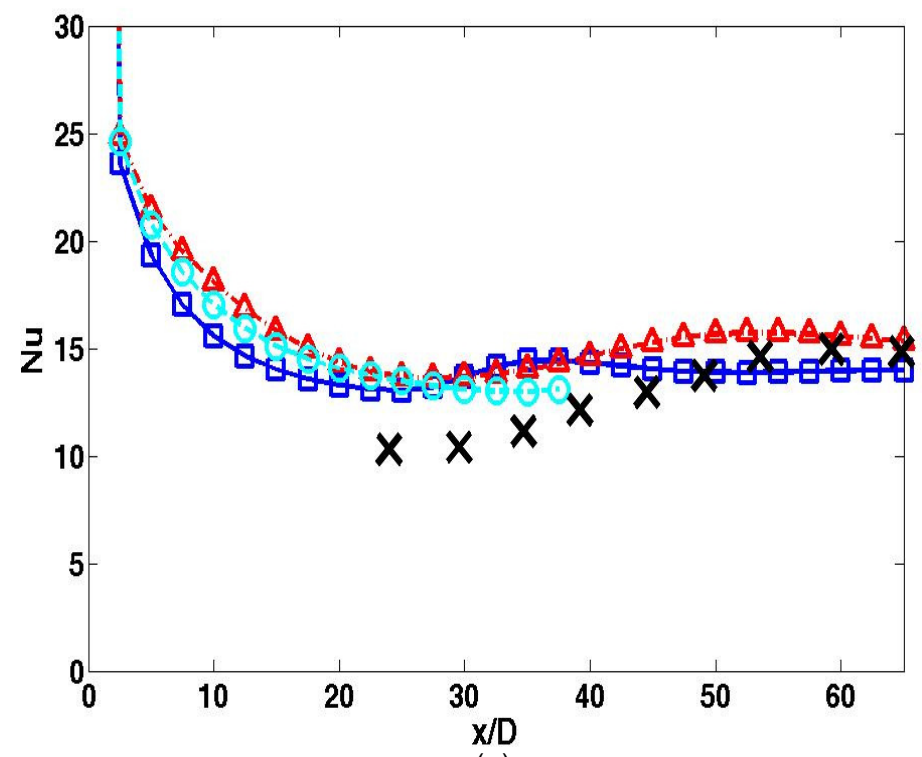

(e)

Figure 6. Nusselt Number Development. (a)-(e): Polyakov and Shindin [6] Runs 1-5 (Table 4) 
[6]. CONVERT is used to run the LS, CI, and Suga models. Conditions at the start of heating are given in Table 4 together with the bulk temperature rise along the test section. In Run $5 \Delta T_{b}$ is sufficiently large to invalidate the Boussinesq approximation, see for example Gray and Giorgini [35]. Comparison with Run 5 is included only for completeness since for these conditions a full variable properties formulation (e.g. Kirwin [14]) should be adopted.

Figure 6 shows plots of Nusselt number against axial position arranged in order of increasing buoyancy influence. Forced convection flow is represented by Fig. 6(a) from which it is seen that the CI model is closest to the measurements, while the Suga and LS models return lower values of $\mathrm{Nu}$. The average value of forced convection Nusselt number obtained from the data of Polyakov and Shindin is $N u_{0}=19.0$ (for $30<x / D<65$ ). Now, Polyakov and Shindin's experiments were conducted for $R e=5100$ (cf. $R e=5300$ in the DNS of You et al. [11]). If $N u_{0}$ is taken to vary as $R e^{0.8}$, the experimental result can be scaled to yield $N u_{0}=19.0 \times(5300 / 5100)^{0.8}=19.6$ at the higher Reynolds number. (The scaled value of $N u_{0}$ appears in Table 2 and Fig. 4, above.) The discrepancy between the scaled experimental value and the value of $N u_{0}$ quoted by You et al. $\left(N u_{0}=18.3\right)$ may raise some question over the accuracy of the DNS.

Table 4. Conditions at the Start of Heating in the Experiments of Polyakov and Shindin [6]

\begin{tabular}{|c|c|c|c|c|c|c|}
\hline Run & $R e$ & $\operatorname{Pr}$ & $G r$ & $B o$ & $q^{+}$ & $\begin{array}{c}\Delta T_{b} \\
\left({ }^{\circ} \mathrm{C}\right)\end{array}$ \\
\hline 1 & 5100 & 0.709 & 0 & 0 & 0 & - \\
\hline 2 & 5100 & 0.709 & $4.80 E+06$ & 0.1010 & $5.64 E-05$ & 4.8 \\
\hline 3 & 5100 & 0.709 & $1.55 E+07$ & 0.3280 & $1.84 E-04$ & 15.6 \\
\hline 4 & 5100 & 0.709 & $3.00 E+07$ & 0.6320 & $3.53 E-04$ & 30.0 \\
\hline 5 & 5100 & 0.709 & $7.67 E+07$ & 1.6190 & $9.01 E-04$ & 76.8 \\
\hline
\end{tabular}

Figures 6(b) and (c) are for values of Bo associated respectively with early-onset mixed convection and heat transfer recovery. The LS model is closest to the data of Fig. 6(b), and, while no model accurately captures the development history of Fig. 6(c), the LS scheme is in best agreement with the measurements made in the downstream region. Further into the recovery region, Fig. 6(d) shows that the LS model performs better than the other two schemes. As indicated previously, variable property effects in Run 5 (Fig. 6(e)) render the Boussinesq approximation inapplicable, and it would be inadvisable to draw any firm conclusions from these results.

\section{CONCLUDING REMARKS}

The present work has examined a number of eddy-viscosity turbulence models against experimental and DNS data for ascending buoyancy-influenced 'mixed' convection. The various turbulence closures adopt a range of different strategies to account for departures from the 'universality' of flow behaviour that is associated with fully-developed forced convection conditions. Thus, for example, 'damping' in the constitutive stress/strain may be made to depend on a local turbulent Reynolds number (the Launder-Sharma model [1]), a dimensionless strain parameter (the CottonIsmael model [19]), or the wall-normal Reynolds stress (the Lien-Durbin [27] and 'Manchester' $\overline{v^{2}}-f$ schemes). Large Eddy Simulation results have also been generated as part of the project.

Initial comparison of the present turbulence model and LES results with forced convection data generated by You et al. [11] produced a somewhat inconsistent picture, whereby a given model might return a reasonably accurate value for Nusselt number, but not local friction coefficient (or viceversa). The situation is compounded further by the observation that the DNS value for $N u_{0}$ is approximately $7 \%$ lower than the experimental measurement of Polyakov and Shindin [6].

The Launder-Sharma turbulence closure was found to be in the closest agreement with the DNS data of You et al. for the ratio of mixed-to-forced convection Nusselt number $\left(\mathrm{Nu} / \mathrm{Nu} u_{0}\right)$, clearly reproducing the large-scale impairment of heat transfer associated with ascending mixed convection flows. The two $\overline{v^{2}}-f$ variants produced the next most accurate results. There is some difference between the current LES results and the DNS data, a matter that is to receive further attention in the course of the research programme (in particular the present authors intend to carry out more refined LES runs). In-house, industrial, and commercial codes (respectively CONVERT [16], Code_Saturne [23], and STAR-CD [21]) were used in this part of the study. Satisfactory agreement between Code_Saturne and STAR-CD was obtained when using the $k-\omega-S S T$ model of Menter [24], although the scheme performed poorly in comparison with data.

The Launder-Sharma, Cotton-Ismael and Suga [20] models were next evaluated in comparison with the data of Polyakov and Shindin [6] for developing forced and mixed convection flows. The Cotton-Ismael scheme was in the best agreement with the forced convection case; however, the Launder-Sharma model was found to be superior in the computation of mixed convection flows. Thus, it does not appear at present that any single turbulence model can be recommended unequivocally for the calculation of the broad flow class under present consideration.

Finally, it must be noted that attention in the present paper has been restricted to the practically important question of heat transfer performance. A more complete assessment of a turbulence model requires an examination of mean flow and turbulence profiles and this will be done in a companion work [22].

\section{ACKNOWLEDGEMENTS}

The authors would like to thank Professor D. R. Laurence for his input to the present project.

This work was carried out as part of the 'Towards a Sustainable Energy Economy' (TSEC) program 'Keeping the Nuclear Option Open' (KNOO) and as such we are grateful to the UK Engineering and Physical Sciences Research Council for funding under grant EP/C549465/1. 


\section{NOMENCLATURE}

Bo Buoyancy parameter, $8 \times 10^{4} \mathrm{Gr} /\left(\operatorname{Re}^{3.425} \operatorname{Pr}^{0.8}\right)$

$c_{f} \quad$ Local friction coefficient

$C_{s} \quad$ The constant for Smagorinsky model

$D \quad$ Pipe diameter

Gr Grashof number, $\beta g D^{4} \dot{q} /\left(\lambda v^{2}\right)$

$k \quad$ Turbulent kinetic energy, $\overline{u_{i} u_{i}} / 2$

$L \quad$ Length scale

$\mathrm{Nu} \quad$ Nusselt number, $\dot{q} D /\left(\lambda\left(T_{w}-T_{b}\right)\right)$

$p \quad$ Pressure

$P_{k} \quad$ Rate of shear production of $k$

$\operatorname{Pr} \quad$ Prandtl number, $c_{p} \mu / \lambda$

$\dot{q} \quad$ Wall heat flux

$q^{+} \quad$ Heat loading parameter, $\dot{q} /\left(\rho_{b} U_{b} c_{p b} T_{b}\right)$

$r, x, \theta \quad$ Cylindrical polar coordinates

$R \quad$ Pipe radius, $D / 2$

Re Reynolds number, $U_{b} D / v$

$R e_{t} \quad$ Turbulent Reynolds number, $k^{2} /(v \widetilde{\varepsilon})$

$R e_{\tau} \quad$ Reynolds number based on frictional velocity, $U_{\tau} D / v$

$\bar{S} \quad$ The resolved rate of strain

$t \quad$ Time

$T \quad$ Temperature

$T_{t} \quad$ Turbulent timescale

$U_{i}, u_{i}$ Mean, fluctuating velocity components in Cartesian tensor notation

$U_{\tau} \quad$ Friction velocity, $\left(\tau_{w} / \rho\right)^{1 / 2}$

$x, y \quad$ Streamwise and wall-normal coordinates

$y^{+} \quad$ Dimensionless distance from the wall, $y U_{\tau} / v$

\section{Greek Symbols}

$\beta \quad$ Coefficient of volumetric expansion

$\Delta \quad$ The filter width for the LES approach

$\varepsilon \quad$ Dissipation rate of $k$

$\tilde{\varepsilon} \quad$ Modified dissipation rate, $\varepsilon-2 v\left(\partial k^{1 / 2} / \partial x_{i}\right)^{2}$

$\kappa \quad$ Von Karman constant

$\lambda \quad$ Thermal conductivity

$\mu \quad$ Dynamic viscosity

$\mu_{t} \quad$ The turbulent viscosity or sub-grid viscosity in LES

$v \quad$ Kinematic viscosity, $\mu / \rho$

$\rho \quad$ Density

$\tau_{w} \quad$ Wall shear stress

$\begin{array}{ll}\text { Subscripts } \\ b & \text { Bulk } \\ t & \text { Turbulent } \\ w & \text { Wall } \\ 0 & \text { Forced convection }\end{array}$

Additional symbols are defined in the text.

\section{REFERENCES}

[1] Launder, B.E. and Sharma, B.I., 1974, “Application of the Energy Dissipation Model of Turbulence to the Calculation of Flow near a Spinning Disc", Lett. Heat Mass Transfer, Vol. 1, pp. 131-138.

[2] Petukhov, B.S. and Polyakov, A.F., 1988, "Heat Transfer in Turbulent Mixed Convection", B.E. Launder (ed.), Hemisphere, Bristol, PA, USA.

[3] Jackson, J.D., Cotton, M.A. and Axcell, B. P., 1989, "Studies of Mixed Convection in Vertical Tubes", Int. J. Heat Fluid Flow, Vol. 10, pp. 2-15.

[4] Steiner, A., 1971, "On the Reverse Transition of a Turbulent Flow under the Action of Buoyancy Forces", J. Fluid Mech., Vol. 47, pp. 503-512.

[5] Carr, A.D., Connor, M.A. and Buhr, H.O., 1973, "Velocity, Temperature and Turbulence Measurements in Air for Pipe Flow with Combined Free and Forced Convection", Trans. ASME C, J. Heat Transfer, Vol. 95, pp. 445-452.

[6] Polyakov, A.F. and Shindin, S.A., 1988, "Development of Turbulent Heat Transfer over the length of Vertical Tubes in the presence of Mixed Air Convection", Int. J. Heat Mass Transfer, Vol. 31, pp. 987-992.

[7] Vilemas, J.V., Polkas, P.S. and Kaupas, V.E., 1992, "Local Heat Transfer in a Vertical Gas-Cooled Tube with Turbulent Mixed Convection and Different Heat Fluxes", Int. J. Heat Mass Transfer, Vol. 35, pp. 24212428.

[8] Shehata, A.M. and McEligot, D.M., 1998, "Mean Turbulence Structure in the Viscous Layer of Strongly-Heated Internal Gas Flows, Measurements", Int. J. Heat Mass Transfer, Vol. 41, pp. 4297-4313.

[9] Parlatan, Y., Todreas, N.E. and Driscoll, M.J., 1996, "Buoyancy and Property Variation Effects in Turbulent Mixed Convection of Water in Vertical Tubes", ASME J. Heat Transfer, Vol. 118, pp. 381387.

[10] Kasagi, N. and Nishimura, M., 1997, "Direct Numerical Simulation of Combined Forced and Natural Turbulent Convection in a Vertical Plane Channel”, Int. J. Heat and Fluid Flow, Vol. 18, pp. 8899.

[11] You, J., Yoo, J.Y. and Choi. H., 2003, "Direct Numerical Simulation of Heated Vertical Air Flows in Fully Developed Turbulent Mixed Convection", Int. J. Heat Mass Transfer, Vol. 46, pp. 1613-1627.

[12] Abdelmeguid, A. M. and Spalding, D. B., 1979, "Turbulent Flow and Heat Transfer in Pipes with Buoyancy Effects", J. Fluid Mech., Vol. 94, pp. 383400.

[13] Cotton, M.A. and Jackson, J.D., 1990, "Vertical Tube Air Flows in the Turbulent Mixed Convection Regime Calculated Using a Low-Reynolds-Number $k-\varepsilon$ Model", Int. J. Heat Mass Transfer, Vol. 33, No.2, pp. 275-286.

[14] Kirwin, P.J., 1995, "Investigation and Development of Two-Equation Turbulence Closures with reference to Mixed Convection in Vertical Pipes", PhD thesis, University of Manchester, UK. 
[15] Kim, W.S., Jackson, J.D. and He, S., 2006, "Computational Investigation into Buoyancy-Aided Turbulent Flow and Heat Transfer to Air in a Vertical Tube", Turbulence, Heat and Mass Transfer, Vol. 5, (Hanjalić, K., Nagano, Y. and Jakirlić, S. (Editors)).

[16] Cotton, M.A., 1987, "Theoretical Studies of Mixed Convection in Vertical Tubes", PhD thesis, University of Manchester, UK.

[17] Leschziner, M.A., 1982, "An Introduction and Guide to the Computer Code PASSABLE", Report, Mech. Eng. Dept., UMIST, Manchester, UK.

[18] Raithby, G.D. and Schneider, G.E., 1979, "Numerical Solution of Problems in Incompressible Fluid Flow: Treatment of the Velocity-Pressure Coupling", Numer. Heat Transfer, Vol. 2, pp. 417-440.

[19] Cotton, M.A. and Ismael, J.O., 1998, "A Strain Parameter Turbulence Model and Its Application to Homogeneous and Thin Shear Flows", Int. J. Heat Fluid Flow, Vol. 19, pp. 326-337.

[20] Craft, T.J., Launder, B.E. and Suga, K., 1996, "Development and Application of a Cubic EddyViscosity Model of Turbulence", Int. J. Heat Fluid Flow, Vol. 17, pp. 108-115.

[21] STAR-CD, 2006, Methodology Manual (version 4.02), Computational Dynamic Limited, CD-Adapco.

[22] Keshmiri, A., Cotton, M.A., Addad, Y. and Laurence, D.R., Billard, F, 2008, "Refined Eddy Viscosity Schemes and LES for Ascending Mixed Convection Flows", To appear in 'CHT-08', Proc. $4^{\text {th }}$ Int. Symp. on Advances in Computational Heat Transfer, Marrakech, Morocco, $11^{\text {th }}-16^{\text {th }}$ May 2008.

[23] Archambeau, F., Mechitoua, N. and Sakiz, M., 2004, "A Finite Volume Method for the Computation of Turbulent Incompressible Flows - Industrial Applications", Int. J. Finite Volumes, Vol. 1(1).

[24] Menter, F.R., 1994, "Two-Equation Eddy-Viscosity Turbulence Models for Engineering Applications", AIAA Journal, pp. 1598-1605.

[25] Wilcox, D.C., 1998, "Turbulence Modelling for CFD”, 2nd edition, DCW Industries, Inc.

[26] Durbin, P. A., 1991, "Near-wall Turbulence Closure Modeling Without Damping Functions", Theoret. Comput. Fluid Dyamics, Vol. 3, pp. 1-13.
[27] Lien, F.S. and Durbin, P.A., 1996, "Non Linear k-ع-v2 Modelling with Application to High Lift", NASA Ames/Stanford University Centre for Turbulence Research, Proceedings of the Summer School Program, pp. 5-25.

[28] Laurence, D.R., Uribe, J.C. and Utyuzhnikov, S.V., 2004, "A Robust Formulation of the $v^{2}-f$ Model", Flow, Turbulence and Combustion, Vol. 73, pp. 169185.

[29] Hanjalić, K., Popovac, M. and Hadziabdic, M., 2004, "A Robust Near-Wall Elliptic-Relaxation EddyViscosity Turbulence Model for CFD”, Int. J. Heat Fluid Flow, Vol. 24, pp. 1047-1051.

[30] Manceau, R., 2005, "An Improved Version of the Elliptic Blending Model. Application to Non-Rotating and Rotating Channel Flows", in Proc. $4^{\text {th }}$ Symp. Turb. Shear Flow Phenomena, Williamsburg, J.A.C. Humphrey et al., eds., Williamsburg, Virginia, USA, pp. 259-264.

[31] Lien, F.S., Chen, W.L., and Leschziner, M.A., 1996, "Low-Reynolds-Number Eddy-Viscosity Modelling Based on Non-Linear Stress-Strain/Vorticity Relations", Proc. 3rd Symp. on Engineering Turbulence Modelling and Measurements, W. Rodi and E. Bergeles, Eds., pp. 91-100, Crete, Greece.

[32] Lilly, D.K., 1966, "On the Application of the Eddy Viscosity Concept in the Inertial Sub-range of Turbulence", NCAR manuscript No.123, National Center for Atmospheric Research, Boulder, CO, USA.

[33] Addad, Y., 2005, "Large Eddy Simulations of Bluff Body, Mixed and Natural Convection Turbulent Flows with Unstructured FV Codes", PhD thesis, Department of Mechanical, Aerospace and Manufacturing Engineering, UMIST (now University of Manchester).

[34] Hall, W.B. and Jackson, J.D., 1969, "Laminarization of a Turbulent Pipe Flow by Buoyancy Forces", ASME Paper, 69-HT-55.

[35] Gray, D.D. and Giorgini, A., 1976, "The Validity of the Boussinesq Approximation for Liquids and Gases”, Int. J. Heat Mass Transfer, Vol. 19, pp. 545551. 